\title{
Influence of Lifelong-Education Theory on the Management of Sports Education in Colleges and Universities
}

\author{
Zhi-Tong CHEN ${ }^{\mathrm{a}}$, Xiang-Liang LI", Yu-Hui CHEN ${ }^{\mathrm{c}}$ \\ ${ }^{1}$ School of Physical Education and Health, ShanghaiLixin University of Accounting and Finance, \\ Shanghai \\ *School of Physical Education and Health, ShanghaiLixin University of Accounting and Finance, \\ Shanghai \\ ${ }^{3}$ School of Finance, ShanghaiLixin University of Accounting and Finance, Shanghai \\ achenzhitong@lixin.edu.cn, "14668518@qq.com, 'chichihuihui77@163.com
}

Keywords: Lifelong, Physical education, Education management, Higher education.

\begin{abstract}
With the continuous improvement and enormous development of economics society, people grasp the positive effect of physical exercises more clearly. People achieve more energy, space and financial resources to focus on their health, and strengthen the awareness of healthy and physical exercises. The adult is the future of the society and school physical education is the basis of lifelong physical education. This is a trend of the management of physical education focused on the lifelong physical education, especially for the higher education institutions. Although there are theories of lifelong physical education, the speed of social development is increasing. Along with the background of Health China, the new change of the reform and development of physical education have come into being.
\end{abstract}

\section{Introduction}

The concept of lifelong physical education was proposed by International Conference on Adult Education in 1960s, which means people could take physical exercises or accept physical education throughout their life.

With the continuous improvement of living standards and cultural degree, people grasp the positive effect of physical exercises more clearly. Whatever, the enormous developments of polity, economy and culture on modern society bring people to increase their income, prolong their life and improve their life's quality. People achieve more leisure times, energy, space and financial supports to take more exercises. Anyway, lifelong physical education is satisfied with contemporary society development. Along with the changes of modern mode of production and lifestyle, it makes a negative impact on people health. As a result of less manual labor activities, quicker life rhythm, more challenging life and excessive intake of heat modern civilization disease occurred, which threatens to people on the health and life seriously. To improve health individual, people strengthen their health and physical exercises awareness. More importantly, physical education has played a considerable role in modern life.

The integration of national fitness and national health, lifelong physical education management reattract public attention on that of higher education institutions. At the stage of higher education, more space and rights are endowed with students. Students have more choices to select and layout their life, which will have a huge influence on their future. Therefore, it is the most pivotal period for students to set up the sense of lifelong physical education, cultivate the interests of physical education and identify with importance of physical exercises and education. 


\section{The Reasons for the Lifelong Physical Education in Higher Education Institutions}

\section{The Demand for Education Reform and Development}

Physical education management is the partial case of physical culture and sports, related to the achievement to the physical works smoothly. With the advancement of education reform and development, a series of higher requirements have been proved to physical education management. Incorporated into the education reform and development, lifelong physical education could improve the efficiency of physical teaching and maintain the vitality of the whole physical work.

Importantly, school sports are the base of lifelong sports, and students are the basic elements of lifelong physical education. Along with the in-depth and multi-level education reform, the high education institution is the spot of the reform in the next terms. Through the purposeful and planned training systematically, students could develop the habit and awareness of taking exercises individually and gradually and lay the foundation of lifelong sports successfully.

\section{The Rapid Development of Market and Society}

Nowadays, with the rapid development of science and technology, high education was required to cultivate the inter-disciplinary talents with innovation and entrepreneurship. What is more, it is easier for human resources market and modern society to accept and absorb high quality talents in enterprising.

Advanced in the whole society, physics is not only a kind of physical or biological movements, but a pluralistic value and function of lifestyle and education method in a long term. Physical education is able to be used for cultivating healthy physique, shaping healthy personality and promote the overall development of people in a continuous and sustainable way.

\section{The Need of All-Round Student Development}

More and more advanced in society, more and more talents are required. As well, talent requirements get more serious and also in details constantly. Except for the relevant professionals with a serious quality, a positive attitude, healthy physique and innovate spirit made up to the latest and comprehensive requirements for modern talents. Anyway, good physical fitness is a prerequisite and assurance for learning and work.

The lifelong physical education makes a considerate basement of all-round development in healthy physique, optimistic attitude and undefeated belief for students. However, students master the sports skills and knowledge through body exercises. Simultaneously, they strengthen their resistance, adaptability and adjustment of pressure step by step.

\section{The Current Status and Problems of the Lifelong Physical Education on the Management of Physical Education in Universities}

Under advancing the physical education reform, it has developed a regular mode to supervise and guide students to take physical exercises and improve their physical fitness. The content of that is routine physical education course, morning jogging, sports club or association activities after class and regular competitive games. Throughout this mode of physical education arrangement, students can spare a few hours to take physical exercises and get physical knowledge. Nevertheless, there are still some problems at the moment.

\section{Limitations of the Course Arrangement and Content}

From the whole view, on the course arrangement and content, although students take one physical exercise course every week in total of almost 2 hours. Compared with other subjects, especially the elective courses, the physical education course has only few hours, leading to the limitations of the knowledge achieved from the course and very little exercises.

Otherwise, for the students in different constitutional pattern, there is the unified teaching content in the same class. The same strength of training has a certain possibility to make part of students 
suffered from sports injury, which makes a negative impact on achieving the effect of reasonable fitness.

\section{Lack of Freedom and Flexibility}

The above mentioned is that most schools urge students to take physical exercises in a prescribed pattern. Added to the less selectable events, the single form and fixed time will give students a feeling of conflict, and then lose the interest. For the most freshmen, physical education course is almost an empty space for their life because of the tight preparation for the college entrance examination. Most of them do not develop the habit of regular exercise, even some of them do not know what kind of sports they like. Moreover, developing or recollecting students' interests of physical exercises is a particularly important thing for physical education management.

For the sports events, most schools position the regular course at the teaching of professional skills. Not everyone fits with the study of professional skills. The study of sport appreciation, prevention and treatment of sports injury, sports regulation is also an important part of physical education in fact. Anyway, as the result of less kind of course arrangement, students have limitations to choose physical events they suited.

\section{Disjoint with Mass Sports}

The mainly group physical activities in campus is about the series of sports competitions, lacking of health education, professional exercise guidance, psychological consultation, physical performance and so on. On the other part, school sports are out of touch with social sports, while the professional physical education talents are limited to the campus courses. Apart from providing professional guidance and teaching to the public, it is the waste of professional physical education talents.

The introduction of Healthy China injects new vitality and impetus into public fitness, promoting the accelerated development and construction of recreational sports. At the same time, a large amount of professional physical talents is needed. The high education institution is the best place to develop public fitness plan with the group activities.

\section{The Reform and Development of Physical Education Management}

\section{Scientificalness of Physical Education Content}

The traditional physical education usually puts forward strict requirements for sports skills. By scoring the proficiency and accuracy of the specific skills, the performance of the students is assessed at the time. It is inappropriate to use the learning effect of a few techniques to evaluate a student in the physical education, because of the individual differences of students. With the introduction of lifelong concept, physical education should be more focused on the long-term changes of students. Not the single mastery of technology but the promotion of comprehensive physical quality, including speed, strength, paroxysmal, muscular endurance, flexibility and so on. From the aspect of management, decreasing the attention to the single skill learning as well as increasing the attention to comprehensive physical quality. Thus, it guide the students to make a progress in a long term, which can cultivate their habit of long time exercises and make lifelong physical education come true.

The physical education is not only about the training for basic skills of certain events, but the cultivation of sports attainment, for example the director of tournament, communication with social associations, appreciation of sports technology and so no. Internet injects vitality into formal physical education, providing the wider network platform. Rely on these beneficial conditions, physical education should be changed to broaden students' horizons except for skills. By means of network technology, physical education should guide students to explore what they want to study on the certain events, and what is the basic skills they should grasp. Throughout autonomous choices, teachers can provide students correctly and timely, otherwise, students can give teachers feedback 
and suggestions actually and valuable. From these real moves, students can take physical education initiatively, develop the regular exercises gradually.

Pay more attention to theory of teaching, strengthen the understanding of sports events. Even if a little lack of athletic ability, students can get the spirit and interpretation of the event, which can be truly involved in the sports activities. Students also can show their gains through media to communicate with classmates and teachers after a period of study. Importantly, teachers can catch the students' learning progress, which is useful to arrange and update the teaching schedule. Indeed, there will build a great relationship between teachers and students, and they all will get benefits form it.

\section{Innovativeness of Physical Teaching Mood}

Along with the advancement of globalization, management of physical education presents the new features of internationalization, diversification and so on. Coupled with the continuous development of Internet science and technology, the teaching mood is also injected into the new blood.

For the sharing of educational resources through the use of network information platform, such as Mooc, micro course and other forms, the traditional teaching mode must be adjusted accordingly. Teachers need to change the teaching thoughts based on "teaching first", find out the problems that students appeared in basic content learning. After that, guide and correct students through more communications and discussions with students. Through the form of partner education, students have improved their ability of self-study and communication in the process of participating in the course. More importantly, during the process of learning, communication and improvement, students experience the sense of achievement and satisfaction brought by sports, which will urge students to regain their enthusiasm for physical exercise, so as to start regular physical exercise and achieve the purpose of lifelong physical education eventually.

\section{Informatization of Physical Education Management}

As the arrival of the Internet+ times, the reform and development of physical education management is more and more inseparable from the network and information technology. Applied in physical education management, the information platform integrates the education and management resources to share with teachers and students, combined with database correctly. From that students can use the online resources to arrange their personal training plan reasonably, aiming to choose the physical exercises suitable. What is more useful to develop and recollect the interest of physical exercises for students, eventually help students to build the belief of lifelong physical education.

With the help of Computer Managed Instruction(CMI) and Computer Assisted Instruction(CAI), physical education become more and more normalized, visual and operable for teachers and students to apply. What can help the furtherance the development, organizational coordination and control and professional competence of professional talents in physical education effectively. Students can use the applications on smart phone to exercise scientifically, get more communication with directors and the exercise progress can be supervised indeed. Above all, it is the significant method for students to develop the habit of taking regular exercises and make its progress guaranteed.

\section{Conclusion}

School physical education is the basis of lifelong physical education. With the rapid development of society and economy market, the lifelong physical education has gradually become one of the important aspects in schools' education reform and development. The aim of the lifelong physical education is to provide long-term healthy guarantee for people facing more and more intensive life pressure. However, nowadays, the society requires talent not only professional, but also in physical and mental health and all-round development. Lifelong physical education is not only the requirement of educational development, but the demand of development of economic market. 
However, the lifelong physical education still has some problems in practice, especially in high education institutions. What cannot be ignored is that the significant effect produced by lifelong health in the society. Hope to provide relevant suggestion, reference and practice for the future development of lifelong physical education on the management of physical education in higher education institutions.

\section{References}

[1] C.H. Zhang. Study on the Entrepreneurship of Innovative Entrepreneurship Education in the Curriculum of Tourism Management in Higher Vocational Education [J]. Commercial Stories.2016

[2] J. Wei. Internet under the Background of Tourism Management Professional Innovation Entrepreneurial Ability Training [J]. Hubei Adult Education College. 2016

[3] G. Chen. The Construction of Physical Education Management Platform based on Informatization [J]. China Management Informationization, 2017, 20(8): 215-216 (in Chinese)

[4] B. Zhong. Research on CMI Applied in School Management of Physical Education [J]. Physical Education, 2015, (10): 58-60 (in Chinese)

[5] N. Zhe. Analysis of the Management of Physical Education in Colleges and Universities - in the Case of Civil Aviation University of China[J]. Physical Education, 2017, (168): 88-89

[6] Y. Zhou. On the Innovation and Entrepreneurship Education of Undergraduate Tourism Management Specialty in Higher Vocational Education[J]. Advances in Social Science, Education and Humanities Research, 2017, (86): 60-64 